\title{
Study of Demographic Profile of Organophosphate Compound Poisoning with Special Reference to Early Versus Late Tracheostomy in Tertiary Care Hospital in Rural Area
}

\author{
M. A. Kawale ${ }^{1}$ - S. H. Gawarle ${ }^{1}$ P. N. Keche ${ }^{2}$ S. V. Bhat ${ }^{1}$
}

Received: 20 March 2017/ Accepted: 23 October 2017/Published online: 11 November 2017

(C) Association of Otolaryngologists of India 2017

\begin{abstract}
Tracheostomy is commonly performed life saving procedure. Organophosphorus compound poisoning is a very common emergency encountered in rural area where major population consists of agricultural workers. Ideal timing of tracheostomy is still controversial. Aim of the study is to assess the advantage of performing early ( $48 \mathrm{~h}-$ 7 days) versus late tracheostomy (8-15 days) with regard to weaning from a ventilator, complications and length of hospital stay. This is a comparative retrospective interventional study in which 100 patients of organophosphorus poisoning who underwent tracheostomy during hospital stay due to prolonged intubation were analyzed. Study subjects were divided into two groups. Each group constitute of 50 patients each. Group A: Early tracheostomy (48 h-7 days) and Group B: Late tracheostomy (8-15 days). Early tracheostomy required a shorter duration of mechanical ventilator support (4-5 days) when compared to late tracheostomy (5-8 days), $p<0.05$ and early tracheostomy facilitate early weaning. There was high incidence of complications in late tracheostomy group as compare to early tracheostomy group. Duration of hospital stay was also longer in Group B (mean 40 days) as
\end{abstract}

\footnotetext{
M. A. Kawale

kawale.megha@gmail.com

S. H. Gawarle

surengawarle@gmail.com

P. N. Keche

drprashantkeche1@gmail.com

S. V. Bhat

drsnehabhat@rediffmail.com

SVNGMC, Yavatmal, Maharashtra, India

2 Government Cancer Hospital, Aurangabad, Maharashtra, India
}

compare to Group A (mean 32 days) with $p<0.05$. We concluded that, early tracheostomy was associated with shorter duration of mechanical ventilator support, it helps for early weaning, shorted intensive care unit and hospital stay as compare to late tracheostomy.

Keywords Tracheostomy - ICU · Length of hospital stay · Organophosphorus poisoning · Weaning .

Mechanical ventilation

\section{Introduction}

Among all the operations a doctor perform on a human being for his cure, one which gives prompt relief of those who are at the point of death, which makes the doctor entirely comparable to God is the opening of trachea whereby the patients who are on the verge of death instantly get relieved and are again able to draw air into the lungs necessary to life and regain life again which they had almost lost.

Tracheostomy is having rich history dated back to multiple centuries. The first known reference comes in "THE RIGVEDA" from approximately 2000 B.C. [1], since then refinement of operation and indication of the procedure has been extensively changed. Until the middle of nineteenth century, tracheostomy was consider as hazards procedure and was rarely performed, however in last 50-60 years the indications of tracheostomy has been expanded. Initially all tracheostomy was carried out only to relieve the upper airway obstruction, gradually its indication became extensive and now it's being increasingly used as temporary procedure for assisted ventilation and for anesthetic purposes. Similarly the indications of long term or permanent tracheostomy as in cases of severe respiratory 
distress, sleep apnea syndrome and terminal malignant neoplasm are also increasing [2].

Tracheostomy is an invasive surgical procedure so but obvious likes any other surgical procedure it is also associated with complications. However, they are less common since the tracheostomy tube bypass the sub-glottis, which is the narrowest part of the airway and the region where complications are likely to arise [3]. It avoids injury to pharynx, larynx and trachea, reduces the dead space and ventilator efforts and make tracheobronchial toilet easier [4].

The timing of tracheostomy is very important. If the tracheostomy can be performed before severe anoxia and irreversible lung damage set in, it greatly simplifies the post operative care reduces the need of mechanical ventilation, and facilitate early recovery [1]. Ideal timing to perform tracheostomy has been controversial topic. Hence present study carried out to find out the advantageous and complications of early tracheostomy versus late tracheostomy.

Present study carried out in rural area as there are plenty of studies available on tracheostomy from urban centers but the same has been lacking for rural area in our country where more than $70 \%$ of the population resides. OP poisoning (Organophosphorus poisoning) with suicidal intention is the major reason for long term mechanical ventilation so to study various parameters, this study was planned at ENT (Ear Nose Throat) Department of Government Medical College and Hospital, Yavatmal, which is situated in tribal area. An attempt has been made to optimizing ideal time of performing tracheostomy in patients requiring long-term mechanical ventilation because of OP poisoning.

\section{Materials and Methods}

The study was a randomized, retrospective, comparative, interventional study which carried out in 500 bedded tertiary care hospital situated in rural area. The aim of the study were to evaluate epidemiological factors regarding OP poisoning, to study effect of early versus late tracheostomy with respect to weaning from mechanical ventilator and length of stay (LOS) in hospital. The study spanned for the period of August 2012 to May 2015. The present study constitute 100 subjects ages 16-68 years of both sex admitted in tertiary care hospital situated in tribal area. All the patients required prolonged intubation due to OP poisoning with APACHE II SCORE (Acute Physiological and Chronic Health Evaluation II Score) $<15$ [5, 6] were included in the study. While those patients who died during the hospital stay and follow up was excluded. 100 patients were randomized into 2 groups. Each group constitutes 50 patients.
Group A: Early tracheostomy (48 h-7 days)

Group B: Late tracheostomy (8-15 days)

The decision to perform tracheostomy and when to perform the procedure depends upon the clinical assessment including the failure to wean, the ability of the patient to "protect the airway and capability of spontaneous cough". Sometimes intensivists judge the patient according to co-morbidities whether patient can sustain the extubation while in some patients failed extubation for 2-3 times may lead to tracheostomy. Since the data were extracted retrospectively from ICU (Intensive Care Unit) database, the decision to perform tracheostomy was not influenced by the study.

\section{Statistical Analysis}

Descriptive statistical analysis was carried out on this study using Chi square test, student $t$ test. Data analysis was carried out using stastical software namely, Stastical Package for Social Sciences (SPSS) 15.0.

\section{Result}

During the study period, 250 adult patients of OP poisoning were admitted in ICU and 100 met the eligibility criterion which makes $36.36 \%$. Open surgical tracheostomy was performed for all the patients included in the study. Mean age group of group A is 32.74 years while for Group B is being 33.38 years. There was male predominance in both groups with Male:Female ratio 3:1. (Table 1) In the present study occupation wise agricultural worker were on top 68 patients followed by labourer 10 patients. The commonest motive of poisoning was suicidal in both males and females. Financial problem was one of the commonest reason of poisoning as most of the patients belongs to low socioeconomic class (Table 1).

After applying statistical analysis unpaired test, we found that Group B required more days of hospital stay as compared to Group A. Statistically significant with t values 31.27, $p<0.0001$ (Table 2).

After applying statistical analysis unpaired " $t$ " test, we found that Group B required more days of mechanical ventilation as compared to Group A. Statistically significant with t values $31.27, p<0.0001$.

So if we compare $>5$ days of assisted ventilation in early tracheostomy Group A is $10 \%$ while $50 \%$ of Group B patients required $>5$ days of ventilation (Table 3 ).

There was a high incidence of complications such as crusting, partial blocked tracheostomy tube and aspiration pneumonia in Group B patients as compare to Group A patients (Fig. 1). 
Table 1 Showing demographic profile of patients

\begin{tabular}{lc}
\hline Age (years) & No of patients \\
\hline $0-20$ & 22 \\
$21-40$ & 52 \\
$41-60$ & 18 \\
$>60$ & 8 \\
Total & 100 \\
Sex ratio & $3: 1$ \\
Occupation & \\
Farmer & 68 \\
Labourer & 10 \\
Household & 8 \\
Students & 8 \\
Others & 6 \\
Total & 100 \\
Socio-economic & \\
Lower class & 90 \\
Middle class & 8 \\
Upper class & 2 \\
Total & 100 \\
Rural & 90 \\
Urban & 10 \\
Total & 100 \\
\hline
\end{tabular}

Table 2 Hospital stay

\begin{tabular}{lll}
\hline No of days & Group A (N) & Group B (N) \\
\hline $21-30$ & 24 & 0 \\
$31-40$ & 27 & 29 \\
$41-50$ & 0 & 22 \\
Mean length & 30 days & 40 days \\
\hline
\end{tabular}

$\chi^{2}$-value $=46.07, p<0.0001$, significant

Table 3 Duration of ventilation after tracheostomy

No of days Group A (N) Group A (\%) Group B (N) Group B (\%)

\begin{tabular}{rrrrr}
\hline 3 & 11 & 22 & 0 & 0 \\
4 & 18 & 36 & 6 & 12 \\
5 & 16 & 32 & 19 & 38 \\
6 & 3 & 6 & 11 & 22 \\
7 & 2 & 4 & 8 & 16 \\
8 & 0 & 0 & 3 & 6 \\
9 & 0 & 0 & 3 & 6 \\
\hline
\end{tabular}

$\chi^{2}$-value $=31.27, p<0.0001$, significant

In this study we found that early tracheostomy group had shorter duration of ventilation $(4.22+1.07)$ versus late tracheostomy group $(5.74+1.29)$ with statistically

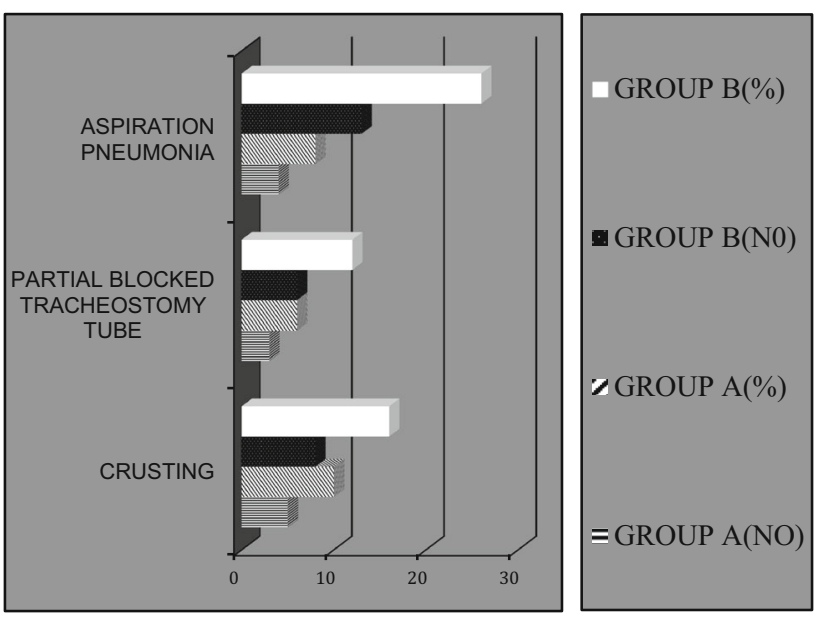

Fig. 1 Early post-operative complications. $\quad \chi^{2}$-value $=1.61$, $p=0.44, \mathrm{NS}, p>0.05$

significant $p<0.05$ and hospital length of stay for Group A $(29.56+4.44)$ versus Group B $(39.82+5.07)$ statistically significant $p<0.05$. Timing for tracheostomy is also significant with $p<0.05$ as well as APACHE score $<15$ is also predictor of duration of ventilation in Group A and Group B with $p<0.05$ (Table 4).

\section{Discussion}

In the present study, we found that majority of patients were in early middle age group, the mean age group being 32 years in Group A and 33 years in Group B. According to present study it is obvious that most of the cases were from young productive age group. This may be because of young productive age group more prone to more emotional and economical constrains. As study carried out in rural area, the majorities are farmer by occupation. So the probable causes of high morbidity and mortality are easily available agricultural pesticide, high toxicity of locally available poisons, difficulty in transporting the patients, paucity of health care worker, lack of training facilities and non-availability of antidotes.

Long-term mechanical ventilation is the most common situation where tracheostomy is indicated for patients in intensive care units (ICU) [7]. Although the definition of prolonged ventilation can include periods as short as $24 \mathrm{~h}$ [8], only patients who are foreseen to be on artificial ventilation for around 10 days or more $[9,10]$ are generally subjected to elective tracheostomy. In this circumstance, tracheostomy is offered as a strategy to reduce respiratory injury and other undesired consequence of prolonged translaryngeal intubation.

Raumbak et al. [11] conducted a study where they randomized 120 medical ICU patients to either early 
Table 4 Predictors of duration of mechanical ventilation duration, ICU and hospital LOS using multivariate analyses

\begin{tabular}{|c|c|c|c|c|c|c|c|}
\hline & Group & $\mathrm{N}$ & Mean & SD & SE mean & $t$ value & $p$ value \\
\hline \multirow[t]{2}{*}{ Duration } & Group A & 50 & 4.22 & 1.07 & 0.15 & \multirow[t]{2}{*}{6.40} & \multirow[t]{2}{*}{$0.000 \mathrm{~S}, p<0.05$} \\
\hline & Group B & 50 & 5.74 & 1.29 & 0.18 & & \\
\hline \multirow[t]{2}{*}{ Hospital LOS } & Group A & 50 & 29.56 & 4.44 & 0.62 & \multirow[t]{2}{*}{10.76} & \multirow[t]{2}{*}{$0.000 \mathrm{~S}, p<0.05$} \\
\hline & Group B & 50 & 39.82 & 5.07 & 0.71 & & \\
\hline \multirow[t]{2}{*}{ Age } & Group A & 50 & 32.74 & 14.21 & 2.01 & \multirow[t]{2}{*}{0.22} & \multirow[t]{2}{*}{$0.81 \mathrm{NS}, p>0.05$} \\
\hline & Group B & 50 & 33.38 & 13.72 & 1.94 & & \\
\hline \multirow[t]{2}{*}{ Time } & Group A & 50 & 3.36 & 1.17 & 0.16 & \multirow[t]{2}{*}{19.97} & \multirow[t]{2}{*}{$0.000 \mathrm{~S}, p<0.05$} \\
\hline & Group B & 50 & 9.86 & 1.979 & 0.27 & & \\
\hline \multirow[t]{2}{*}{ Apache score } & Group A & 50 & 40.88 & 3.03 & 0.42 & \multirow[t]{2}{*}{8.04} & \multirow[t]{2}{*}{$0.000 \mathrm{~S}, p<0.05$} \\
\hline & Group B & 50 & 32.00 & 7.19 & 1.01 & & \\
\hline
\end{tabular}

tracheotomy (within $48 \mathrm{~h}$ ) or delayed tracheotomy (at days 14-16). They found that the early tracheotomy group had shorter mechanical ventilation duration $(7.6 \pm 2.0$ vs. $17.4 \pm 5.3$ days $)$ and ICU LOS (4.8 \pm 1.4 vs. $16.2 \pm 3.8$ days) as well as less mortality (31.7 vs. $61.7 \%$ ) [11]. The study used an APACHE II score of greater than 25 as an inclusion criterion, which limits the generalize ability to patients who are less critically ill. Terragni et al. [12] randomized 51 patients to early tracheostomy (within 7 days of intubation) and 55 patients to late tracheostomy ( $>7$ days) and found that early tracheostomy was associated with a decrease in mechanical ventilation duration (12 vs. 32), ICU LOS, and hospital LOS.

Rodriguez et al. [13] observed that $67.6 \%$ (142/210) of patients from the late tracheostomy group and 77\% (161/ 209) from the early group experienced a successful weaning. Thus, it was possible to estimate a statistically significant higher proportion of patients with successful weaning in the early tracheostomy group as compared to the late tracheostomy group (RR 0.88 , 95\% CI 0.78-0.99, $p=0.03$, one study). He also measured the median values of ventilator-free days at 28th day, which is considered a good outcome. The results showed statistically significant ( $p=0.02$ ) estimated effects favoring early tracheostomy (median 11 days, interquartile range 0-21 days) as compared to late tracheostomy (median 6 days, interquartile range 0-17 days). Arabi et al. [14] found that the duration of mechanical ventilation was significantly shorter (9.6 vs. 18.7 days) when tracheostomy was performed within 7 days. Lesnik et al. [15] retrospectively studied 101 patients with blunt multiple trauma and found that early tracheostomy (performed within 4 days of intubation) was associated with shorter mechanical ventilation duration. Armstrong et al. [9] performed a retrospective chart review of 157 patients with blunt trauma and found that early tracheostomy ( $<6$ days of intubation) was associated with decrease in ICU and hospital LOS. D'ameloi et al. [16] studied 43 patients with trauma respectively, 3 of whom underwent tracheostomy. Patient who had tracheostomy done within first 7 days of intubation had shorter mechanical ventilation duration as well as ICU and hospital LOS. Bouderka et al. [17] prospectively studied 62 patients with trauma with isolated head injury who were randomized into 2 groups: early tracheostomy group (5th-6th day, $\mathrm{n}=31$ ) and late tracheostomy group (after the 6th day). The investigators found that the mechanical ventilation duration was shorter in the early tracheostomy group. There was no difference in the frequency of pneumonia or mortality between the 2 groups. Similar finding were in the study by Brook et al. [18] who showed that those subjects who underwent early tracheostomy (less than 10 days, mean 5.9 days) with that or late tracheostomy (greater than 10 days, mean 16.7 days) showed a decreased in both duration of mechanical ventilation (28.3 vs. 34.4 days) and ICU length of stay (15.6 vs. 29.3 days). This was reflected in a lower cost of hospitalization $(\$ 86,189$ vs. $\$ 124,649)$ for the patients who received tracheostomy within 10 days [18]. In the study from our centre, we examined the impact of early versus late tracheostomy in 100 patients of OP poisoning who underwent tracheostomy. We found that duration of mechanical ventilation and length of hospital stay is shorter in early tracheostomy as compare to late tracheostomy group. The main finding of this study contradicts finding from previous relevant well-undertaken studies. In brief, Surgerman et al. [19] conducted a prospective randomized multicenter study of 157 patients, all but 18 of who were patients with trauma. Patients were randomized on days 3-5 to receive tracheostomy or to continue with translaryngeal intubation. Patients who remained intubated were randomized again on days 10-14. They found that ICU LOS did not differ between the 2 groups. Griffith et al. [20], Dunham and Ransom [21], Wang et al.[22] did not show any significant protective 
effect of early versus late tracheostomy on mortality of critically ill patients.

Our study evaluated relationship between time to tracheostomy and duration on mechanical ventilation as well as ICU, LOS as far as complications are concern, our study found that there is high incidence of complication like crusting, partial tube blockage, aspiration pneumonia were more in late tracheostomy group as compare to early tracheostomy group. This may be due to fact that pronged pressure due to endotracheal tube leads to ischemia and necrosis. This observation has been supported by Major et al. [23], Bylappa et al. [24], Hsu et al. [25] found there were a reduction of ventilatory dead space and less airway resistance with a tracheostomy as compared to a translaryngeal tube. Vocal cord palsy is more in late tracheostomy patients due overinflated cuff causing microcirculatory insufficiency. Some pathological changes like erythema, ulceration; granuloma may induce vocal cord immobility. A possible etiology for vocal fold immobility resulting from intubation includes recurrent nerve injury from compression. Both Brandwein et al. [26] and Cavo [27] found the recurrent laryngeal nerve vulnerable to compressive injury between the inflated cuff of the endo-tracheal tube and the thyroid cartilage. Additional possible etiologies for vocal fold immobility after prolonged intubation include myopathy/myositis of the intrinsic laryngeal muscles [16] or arytenoid dislocation [17]. We suggest that cricoarytenoid joint inflammation could also explain vocal fold immobility after intubation. By doing follow up, we found that the long term complications are greater in the late tracheostomy group such as vocal cord fixity secondary to arytenoid subluxation (10\%) compare to $4 \%$ patients of vocal cord fixity. In our study total 5 patients of subglottic stenosis were found comprising $4 \%$ in early tracheostomy patients and $6 \%$ in late tracheostomy patient. The benefits associated with tracheostomy contributed to better weaning from ventilatory support, improved bronchial suctioning and psychological advantages for the severely ill and recovering ICU patients. We have not studied association of time to tracheostomy with mortality as all patients who died during study were eliminated from the study. Therefore those patients who are deemed to likely require tracheostomy, it might be prefer to perform tracheostomy early rather than late tracheostomy. We can interpret the study according to merits and demerits. Merits of the study are large number of patients included in the study, study carried out in rural area where the scenario of indication and technical availability is totally different from urban centers, study included only OP poisoning patients as similar studies are lacking for OP poisoning patients. Limitations included single centered study; underlying co-morbidities can also affect the duration of mechanical ventilation and hospital length of stay.

\section{Conclusion}

We would like to conclude that early tracheostomy facilitate shorter duration of mechanical ventilatilatory support and hospital length of stay. Thus it facilitate early weaning, a shorter stay in the hospital and cost effective compared to late tracheostomy.

Acknowledgement The authors would like to thank the department of ENT, Surgery, other staff of operation theatre and administration of Shri Vasantrao Naik Government Medical College, Yavatmal, Maharashtra, for permission to study and providing facility to carry out the work.

\section{Compliance with Ethical Standards}

Conflict of interest All author declare that they have no conflict of interest.

Ethical Approval Permission of Institutional Ethics Committee was taken and written and informed consent was obtained from the patient or his relatives/parents (in case of minor) before starting the tracheostomy procedure. All procedures performed in studies involving human participants were in accordance with the ethical standards of the institutional and/or national research committee and with the 1964 Helsinki declaration and its later amendments or comparable ethical standards. For this type of study formal consent is not required.

\section{References}

1. Pracy P (2008) Tracheostomy in Scott-Brown's otolaryngology. In: Head and neck surgery, 7 th edn, vol 2. Hodder Arnold

2. Bradley PJ (1997) Management of the obstructed airway and tracheostomy. In: Scott-Brown's otorhinolaryngology, head and neck surgery 6 th edn, vol 5. Butterworth-Heinemann

3. Klunge S, Baumann HJ, Maier C, Klose H, Meyer A, Nierhaus A, Kreymann G (2008) Tracheostomy in intensive care unit: a nationwide survey. Anesth Analg 107(5):1639-1643

4. Boubaker C, Abdelhamid H, Abdellatif B et al (2009) Tracheostomy versus prolonged intubation in medical intensive care unit. Signa Vitae 4(1):21-23

5. Zheng X, Zhu J, Yu Q (2011) Current situation and advance of APACHE-II score in clinical application. Med Recapitulate 21:034

6. Sam KG, Kondabolu K, Pati D, Kamath A, Kumar GP, Rao PG (2009) Poisoning severity score, APACHE II and GCS effective clinical indices for estimating severity and predicting outcome of acute organophosphorus and carbamate poisoning. J Forensic Leg Med 16:239-247. https://doi.org/10.1016/jflm.2008.12.2004

7. Heffner JE, Hess D (2001) Tracheostomy management in the chronically ventilated patient. Clin Chest Med 22(1):55-69

8. Criner GJ, Tzouanakis A, Kreimer DT (1994) Overview of improving tolerance of long-term mechanical ventilation. Crit Care Clin 10(4):845-866

9. Armstrong PA, McCarthy MC, Peoples JB (1998) Reduced use of resources by early tracheostomy in ventilator-dependent patients with blunt trauma. Surgery 124(4):763-766

10. Plummer AL, Gracey DR (1989) Consensus conference on artificial airways in patients receiving mechanical ventilation. Chest 96(1):178-180

11. Rumbak MJ, Newton M, Truncale T, Schwartz SW, Adams JW, Hazard PB (2004) A prospective, randomized, study comparing 
early percutaneous dilational tracheotomy to prolonged translaryngeal intubation (delayed tracheotomy) in critically ill medical patients. Crit Care Med 32(8):1689-1694

12. Terragni PP, Antonelli M, Fumagalli R, Faggiano C, Berardino M, Pallavicini FB et al (2010) Early vs late tracheotomyfor prevention of pneumonia in mechanically ventilated adult ICU patients: a randomized controlled trial. JAMA 303(15):1483-1489

13. Rodriguez JL, Steinberg SM, Luchetti FA, Gibbons KJ, Taheri PA, Flint LM (1990) Early tracheostomy for primary airway management in the surgical critical care setting. Surgery 108(4):655-659

14. Arabi Y, Haddad S, Shirawi N, Al Shimemeri A (2004) Early tracheostomy in intensive care trauma patients improves resource utilization: a cohort study and literature review. Crit Care 8(5):R347-R352

15. Lesnik I, Rappaport W, Fulginiti J, Witzke D (1992) The role of earlytracheostomy in blunt, multiple organ trauma. Am Surg 58(6):346-349

16. D'amelio LF, Hammond JS, Spain DA, Sutyak JP (1994) Tracheostomy and percutaneous endoscopic gastrostomy in the management of the head injured trauma patient. Am Surg 60(3):180-185

17. Bouderka MA, Fakhir B, Bouaggad A, Hmamouchi B, Hamoudi D, Harti A (2004) Early tracheostomy versus prolonged endotracheal intubation in severe head injury. J Trauma Acute Care Surg 57(2):251-254

18. Brook AD, Sherman G, Malen J, Kollef MH (2000) Early versus late tracheostomy in patients who require prolonged mechanical ventilation. Am J Crit Care 9(5):352-359

19. Sugerman HJ, Wolfe L, Pasquale MD, Rogers FB, O'Malley KF, Knudson M et al (1997) Multicenter, randomized, prospective trial of early tracheostomy. J Trauma Acute Care Surg 43(5):741-747

20. Griffiths J, Barber VS, Morgan L, Young JD (2005) Systematic review and meta-analysis of studies of the timing of tracheostomy in adult patients undergoing artificial ventilation. BMJ 330(7502): 1243

21. Dunham CM, Ransom KJ (2006) Assessment of early tracheostomy in trauma patients: a systemic review and metaanalysis. Am Surg 72:276-281

22. Wang F, Wu Y, Bo L et al (2011) The timing of tracheostomy in critically ill patients undergoing mechanical ventilation: a systemic review and meta-analysis of randomized controlled trials. Chest 140:1456-1465

23. Major KM, Hui T, Wilson MT, Gaon MD, Shabot MM, Margulies DR (2003) Objective indications for early tracheostomy after blunt head trauma. Am J Surg 186(6):615-619 (discussion 619)

24. Bylappa K, Mohiyudin A, Delphine W, Silivia CR, Krishnamurthy D, Pyarajan MS (2011) A comparative study f early and late tracheostomy in patients requiring proloned tracheal intubation. Dec 31, 2011. http://www.waent.org/archives/2011/vol42/20111215-Treacheostomy-Intubation/late-tracheostomy.Htm. Accessed 11 May 2014

25. Hsu CL, Chen KY, Chang CH, Jerng JS, Yu CJ, Yang PC (2005) Timing of tracheostomy as a determinant of weaning success in critically ill patients: a retrospective study. Crit Care 9(1):R46R52

26. Brandwein M, Abramson AL, Shikowitz MJ (1986) Bilateral vocal cord paralysis following endotracheal intubation. Arch Otolaryngol Head Neck Surg 112:866-882

27. Cavo JW Jr (1985) True vocal cord paralysis following intubation. Laryngoscope 95:1352-1359 